\title{
CONSTITUIÇÃO DO SER E DO ESTAR NA DOCÊNCIA: OLHARES AO PIBID NA FORMAÇÃO DE PROFESSORES
}

\author{
Neli Aparecida Gai ${ }^{1}$ \\ Robson Olivino Paim²
}

\section{INTRODUÇÃO}

A docência e a formação de seus profissionais constitui o cerne da qualificação do processo educacional. No âmbito das políticas públicas, dentre outros, o Programa Institucional de Bolsas de Iniciação à Docência (Pibid) constitui política de valorização da profissão e da profissionalização docente coadunando-se aos objetivos e práticas dos cursos de formação inicial de professores no âmbito do ensino superior e com as práticas didático-pedagógicas desenvolvidas por professores em escolas de educação básica. Este trabalho busca analisar as aprendizagens do ser e do estar na docência constituídas desde a experiência de três segmentos envolvidos em um subprojeto de uma universidade comunitária catarinense: bolsistas de iniciação à docência, ex-bolsistas, hoje professores da educação básica e estudantes dos anos iniciais do ensino fundamental básica partícipes do Programa.

Este estudo teve como principal objetivo analisar as ações desenvolvidas por este grupo de pessoas que direta ou indiretamente contribuiu para 0 desenvolvimento e o êxito do Programa. A pesquisa foi desenvolvida baseando-se na utilização de entrevistas semiabertas aplicadas a bolsistas de iniciação à docência e a professores de uma escola de educação básica, localizada em um município do oeste catarinense que atende, em sua maioria, estudantes em condição de vulnerabilidade social e econômica. Também foram aplicados questionários com questões abertas e fechadas para 86 estudantes do ensino fundamental - anos iniciais, partícipes do processo na escola. Os resultados das entrevistas foram analisados, em abordagem qualitativa, a partir da metodologia de análise de conteúdo (BARDIN, 2011), enquanto os questionários também receberam o tratamento dos dados via análise de conteúdo, porém, com abordagem mista. Os

\footnotetext{
${ }^{1}$ Universidade do Oeste de Santa Catarina - neli.gai@unoesc.edu.br.

${ }^{2}$ Universidade Federal da Fronteira Sul - robson.paim@uffs.edu.br.
} 
resultados foram categorizados de acordo com o setor de atuação dos sujeitos no Programa (Bolsista de Iniciação à Docência, professor ou estudante da educação básica), atentando para as especificidades no que tange as suas ações, aprendizagens e transformações ao longo do processo, bem como as sugestões de melhorias nos encaminhamentos a fim de suprir as demandas existentes nos planos pessoal, profissional e institucional subjacentes ao processo em análise.

\section{CONSTITUIÇÃO DO SER E DO ESTAR NA DOCÊNCIA}

O grupo Pibidiano desenvolve atividades com interesse em despertar no educando a consciência dele próprio ser o agente na construção de seu conhecimento, necessitando de estímulos e motivação, recebidos assim através de atividades lúdicas. As acadêmicas trabalham sempre de forma responsável, compromissada e sem medir esforços para contribuir com as necessidades da escola e ao mesmo tempo, para vivenciar experiências da prática escolar que contribuem significativamente para a formação inicial.

Diante então deste contexto social da escola, a fim de ampliar o rendimento escolar e torná-lo significativo através de um atendimento individualizado que desenvolva as habilidades do educando, é que o Pibid entra com um leque de estratégias diversificadas, com ações teórico metodológicas que incluem o lúdico, a música e o material concreto, privilegiando assim o aluno a aprender de forma diferenciada e descontraída. Tendo em vista que devem ser respeitadas as fases de desenvolvimento e o tempo de aprendizagem de cada um, inserindo todos no processo de alfabetização e letramento.

Podemos afirmar que o Pibid em nossa escola é uma proposta que está obtendo sucesso, pois a cada dia que passa os educandos sentem mais prazer de frequentar o reforço escolar. Acreditamos que os objetivos do Programa estão sendo alcançados, pois se observa avanços no processo da alfabetização e do letramento e também como um riquíssimo aprendizado para as acadêmicas bolsistas em sua formação tanto profissional quanto pessoal, este vínculo com a realidade escolar e troca de experiências torna-se decisivo para a construção de um bom professor.

A partir deste apanhado inicial que propôs esclarecer o processo de iniciação do Programa Institucional de Iniciação à Docência e sua progressões até o presente momento que surgiu a necessidade de estar comprovando através de 
dados adquiridos em uma pesquisa realizada no final do segundo semestre de 2013, com os três segmentos ligados diretamente ao Programa, sendo eles:as acadêmicas bolsistas que participaram do programa durante sua formação docente e que hoje estão inserias profissionalmente no mercado de trabalho; os professores regentes de turmas que contribuíram para a formação profissional das acadêmicas a partir da socialização de suas práticas pedagógicas e os alunos que foram atendidos no contra turno escolar pelas acadêmicas e puderam com este auxílio superar suas dificuldades.

Esta pesquisa teve como principal objetivo estar analisando e refletindo sobre as ações desenvolvidas por este grupo de pessoas que direta ou indiretamente contribuíram para o êxito do programa, a partir de dados da pesquisa quantificados e qualificados e que buscamos apresentar-lhes para, a partir disso, proporcionar mudanças para o aprimoramento e redirecionamento do Programa, se assim se mostrar necessário.

Passado os anos da década de 1970, onde o ensino apresentava metodologias onde os professores visavam controle e racionalização do ensino escolar e de sua atuação profissional,se impulsionam nos anos80, com reformas educativas no intuito de valorizar o currículo escolar, o funcionamento, a organização e a gestão escolar.

Neste contexto então, não se foge às questões ligadas ao trabalho docente, bem como as dificuldades enfrentadas no processo de ensino aprendizagem, cujo tema nos remete e nos instiga até hoje a difundir reflexões.

Com essa mudança nos anos 80 , sente-se a necessidade de inovar, buscar novas metodologias de ensino que valorizasse mais o educando, como nos diz Nóvoa (2009, p.13) "elementos insubstituíveis não só na promoção e aprendizagens, mas também na construção de processos de inclusão que respondam aos desafios da diversidade e no desenvolvimento de métodos apropriados e de novas tecnologias".

Para que haja aprendizagem significativa, corpo docente e discente precisam estar engajados, assumindo seu compromisso com a educação, unindo a práxis pedagógica com a prática dialética, buscando valorizar ainda mais a formação inicial e continuada.

A valorização do profissional docente também é ponto chave a ser discutido, refletindo assim sobre o empobrecimento das práticas de ensino. Como 
transformar os saberes em inovações pedagógicas? Como adentrar neste meio pedagógico com a capacidade se superar resquícios tradicionalistas ainda existentes em sala de aula? Nóvoa (2009, p.19) aponta três medidas, contribui com a primeira dizendo: formar os professores dentro da profissão; movimentos pedagógicos de organização da formação continuada de professores dentro da organização escolar e; o reforço da dimensão pessoal do professor no que se refere ao ser e ao agir de cada um no desenvolvimento das suas atividades: Seria fundamental se fosse reforçado a identidade profissional para que "os professores se apropriem dos processos de mudança e os transformem em práticas concretas de intervenção" (NÓVOA, 2009, p. 21).

Em muitos casos, a formação continuada vem alimentada tão somente pela quantidade de certificações, não pelo compromisso profissional.Ainda há distanciamentos entre teoria e prática como afirma Nóvoa (2009, p. 24), e ainda destaca que "o trabalho de formação deve estar próximo à realidade escolar e dos problemas sentidos pelos professores". Para o mesmo autor, enquanto se esperam as mudanças, há excesso de discursos e pobreza nas práticas pedagógicas. 0 professor comprometido com o ensino precisa sair de seu círculo vicioso, ao qual está muitas vezes submetido e fazer tal reflexão: O que é um bom professor?

Um bom professor tem impregnado em um sua própria personalidade, três características principais, que foram definidas por Nóvoa (2009, p.29) como trilogia clássica, sendo elas: saber (conhecimentos), saber fazer (capacidades), saber ser (atitudes). No contexto atual, frente às modernidades existentes, o indivíduo deve receber uma formação integral (física, psíquica, social material e afetiva), pois a escola é um espaço de vivências, experiências e aprendizados, importantíssima para a construção e seres sociais ativos na prática da cidadania. "É uma organização centrada na aprendizagem[...] e ainda remete -se a uma escola transbordante" (NÓVOA, 2009, p. 60), pois assume inúmeros papéis que não the compete, mas que a sociedade cobra o que acarreta um distanciamento do seu foco que é a sistematização e construção de saberes.

A aprendizagem não se dissocia do contexto em que o indivíduo vive. É necessário levar em conta tudo aquilo que acontece na vida de cada criança, além da realidade escolar. Isso influencia e muito no desenvolvimento cognitivo e intelectual do indivíduo. É um processo simultâneo, onde se deve respeitar as 
diferentes aprendizagens para que haja sucesso neste processo de construção e elaboração de conceitos e significados.

\section{PIBID: OPORTUNIDADE DE TRANSFORMAÇÃO DE SI E DO OUTRO}

\section{OPIBIDIANO E A RELAÇÃO CONSIGO MESMO}

Para tornar a argumentação mais clara, apresentamos esses depoimentos organizados em três unidades de sentido.

Primeiramente traremos a fala das ex-acadêmicas bolsistas do Programa, como forma de evidenciar a troca de experiências e o trabalho colaborativo entre Universidade e Escola pode estar firmado sim em laços concretos de cooperação, pois a partir do contato das acadêmicas bolsistas no ambiente escolar real, e neste contato o encontro com professores com experiências concretas no ato de ensinar, falando principalmente da alfabetização, é que torna-se significativa a formação docente, pois estes professores podem socializar sua práticas pedagógicas e falar com propriedade sobre a sala de aula, sabendo dos desafios que os professores atuais encontram, seja este colocado pelas novas tecnologias ou pelos processos de inclusão que a diversidade social hoje exige.

Desta forma, Nóvoa (2009, p. 17) contribui muito em sua fala quando diz que "é preciso passar a formação para dentro da profissão". Ao recorrer a esta expressão, quero sublinhar a necessidade de os professores terem um lugar predominante na formação de seus colegas. Não haverá nenhuma mudança significativa se a comunidade dos formadores de professores e a comunidade dos professores não se tornarem mais permeáveis e imbricadas.

Acreditamos que esta lacuna que faltava ser preenchida dentro da formação docente, de dividir com os professores a formação de seus futuros colegas,pois eles, mais do que ninguém, são pessoas indicadas a apontar o caminho. O tempo em que as ex-bolsistas participaram deste Programa influência, com muito êxito, na sua formação profissional, a partir da análise do questionário respondido por seis ex-acadêmicas bolsistas. Dentre elas, duas participaram um ano e meio do Programa, uma participou por dois anos e meio e três participaram por três anos do Programa. 
Levando em consideração o tempo vivenciado por estas seis acadêmicas bolsistas é que se tornou pertinente saber se o Pibid trouxe experiências que poderiam ser aplicadas na prática pedagógica de cada uma delas e quais seriam. Todas as ex-acadêmicas bolsistas entrevistadas analisaram de forma positiva a participação de cada uma delas no Pibid, sendo que este colaborou muito para o crescimento profissional de cada uma delas, adquirindo experiências relevantes para a sua prática pedagógica, sendo experiências a partir de atividades lúdicas, como contação de histórias, que contemplassem a leitura e a escrita.

Outro dado que merece destaque é que todas as ex-acadêmicas bolsistas entrevistadas avaliaram como positiva a participação delas no Pibid para a sua formação acadêmica. Apenas uma bolsista expôs que, em anos anteriores à formação delas, somente era possível relacionar ateoria com a prática em momentos de estágio ou após estarem formadas, quando conseguisse aulas.

Percebeu-se também que todas as entrevistadas consideram positiva a prática pedagógica construída através do Pibid para a sua construção da identidade profissional, sendo positiva a contribuição entre teoria e prática.

Como última análise, temos que destacar alguma dificuldade encontrada pelas bolsistas durante o tempo de atuação no Pibid. Das entrevistadas apenas uma ex-acadêmica bolsista apontou como desfavorável o deslocamento até a escola, devido à distância existente entre sua casa e a escola onde realizava as atividades do Programa. As demais dificuldades enumeradas foram ainfrequência nas aulas, reforço escolar por parte de alguns alunos, dificultando o rendimento nos conteúdos e na apropriação de conceitos, também a recusa, por parte de alguns professores, de aceitar o trabalho das acadêmicas, além é claro, da dificuldade em estar lidando com situações pouco corriqueiras em seu dia a dia, pois tudo, ou quase tudo, no momento era novidade.

A partir da análise de todos estes dados percebe-se claramente que as ações até então desenvolvidas pelo Pibid na Escola de Ensino Fundamental Dom Oscar Arnulfo Romero, contribuíram muito para a formação destas ex-acadêmicas bolsistas do Programa e para estas que ainda participam, pois todas as respostas foram favoráveis a esta prática docente pedagógica na escola. Isto, certamente contou com o encaminhamento da coordenadora institucional em dar direcionamentos pertinentes, enquanto formadora institucional, e com o incansável 
trabalho de orientação pedagógica da supervisora escolar, pois é a partir de um grupo coeso que se constrói um caminho de sucesso e aprendizagens.

Além do trabalho coletivo ter alcançado um bom êxito, os dados coletados na pesquisa apontam para o avanço na qualificação da formação das bolsistas acadêmicas licenciadas, através das atividades desenvolvidas pelo Pibid na referida escola. Assim, relata a ex-acadêmica Géssica Otto: "Desde o início percebi que para conseguir alcançar os objetivos do programa eu deveria aprender a elaborar atividades que fossem relevantes. Com as práticas do Pibid, foi possível ter mais clareza do que era aprendido na faculdade, refletindo nas minhas práticas de estágio".

Certamente esta contribuição do programa vem interferindo positivamente não só na formação docente, mas na realidade escolar enquanto contribuição das acadêmicas a partir de novas metodologias e também no progresso e nas aprendizagens ampliadas.

\section{OPIBIDIANO E A RELAÇÃO COM O PROFESSOR DA ESCOLA}

Ao serem questionados a respeito da importânciado programa PIBID na escola, os professores foram unânimes em responder que é um Programa muito importante, pois auxilia nas dificuldades dos alunos, melhorando a aprendizagem dos mesmos e ainda, para as acadêmicas, o programa dá suporte prático para o ingresso na sala da aula, reforçando a relação entre teoria e prática.

Em relação aos critérios utilizados para que o aluno participe das aulas de reforço, a maioria dos professores responderam que o diagnóstico é feito pelas dificuldades da criança em avançar na aprendizagem, na leitura, escrita, cálculos matemáticos e interpretação de textos.

No que diz respeito às mudanças que são percebidas em relação as crianças que participam das aulas de reforço, os professores relatam que há avanços,porém, consideram que o tempo de reforço é pouco, poucas aulas, pois é o único apoio e estimulo que as crianças recebem fora da sala de aula.

Questionados sobre a maneira que avaliam a participação das acadêmicas na monitoria em sala de aula, a maioria respondeu que o resultado é positivo, e relatam que alem do atendimento individualizado ao aluno, percebe-se nas acadêmicas boa vontade, iniciativa e esforço. Importante destacar que em uma 
das salas não existe monitoria, por esse motivo não obtivemos resposta dessa professora.

$\mathrm{Na}$ questão que se refere ao envolvimento e relação entre os professores regentes e as acadêmicas bolsistas que atendem os alunos com dificuldades de aprendizagem, os professores questionados avaliam que a relação é boa, pois conseguem trocar informações, há dialogo estabelecido entre eles. Um dos sujeitos destaca que deve-se" continuar com esse trabalho e também conscientizar os pais da importância do reforço". Outro sujeito afirma que "acredita que o programa é bem elaborado e bem diversificado e deverá permanecer".

Quando solicitados a dar sugestões de trabalho para as acadêmicas melhorarem os resultados das aulas de reforço, os professores regentes afirmaram que o trabalho que esta sendo desenvolvido já apresenta resultados e por isso deve ser mantido. Destacaram a importância de manter o diálogo entre as acadêmicas e os professores regentes, para que juntos possam encontrar estratégias que venham ao encontro das dificuldades de aprendizagem de cada aluno.

\section{O PIBIDIANO E A RELAÇÃO COM O ALUNO}

Ao relatar sobre o tempo em que os alunos frequentam ou frequentavam o reforço, a maioria deles responderam que fazem de um a dois anos e a outra parte ficou dividida em menos de um ano, e dois a três anos.

No que diz respeito à participação nas aulas de reforço, se auxiliou os educandos em sua aprendizagem, a maior parte respondeu que sim, apenas 3 de 86 entrevistados responderam que as aulas de reforço não ajudaram em sua aprendizagem. Em justificativa a sua afirmação, os educandos que responderam que sim, acreditam que,com as aulas de reforço, passaram a gostar de atividades que não gostavam antes e aprenderam mais, pois, todo dia ganhavam livros novos para ler.

As atividades desenvolvidas ajudam muito em suas aprendizagens, como: escrita, cálculos, leitura, interpretação e separação de sílabas, ainda aprenderam com jogos e brincadeiras novas.

Os alunos que afirmaram que não houve melhoria na aprendizagem alegaram que a professora passava atividades muito fáceis, outro, que não 
frequentava todas as aulas e por isso não aprendia, alegou não estar conseguindo aprender português direito.

Ao questionarmos os educandos sobre como eles mais gostavam de aprender, a maioria dos educandos respondeu que gostam muito de contação de histórias, citaram também jogos, brincadeiras e pinturas como formas de prender a atenção deles nas aulas e despertar o gosto pelo aprender.

Ao se autoavaliarem sobre sua participação e colaboração nas aulas de reforço, alguns alunos disseram que em alguns momentos preferiam ter se esforçado mais, outros afirmam que sempre prestam muita atenção e se esforçam muito, também que as aulas devem continuar, pois ajuda muito a melhorar sua aprendizagem. As respostas ficaram bem divididas em relação a participação nas aulas,já outra parte respondeu que não compareciam muito as aulas e esse era um dos motivos deles não superarem suas dificuldades.

A participação efetiva do projeto Pibid nas escolas vem ao encontro do desenvolvimento dos nossos educandos, tem como intuito contribuir na superação da defasagem da aprendizagem trazendo maneiras dinâmicas e diferentes das que os alunos estão habituados em sala de aula, com o objetivo de estimular em cada aluno a vontade de aprender sempre mais, reforçando suas capacidades cognitivas e contribuindo no seu desenvolvimento.

Para os alunos os encontros realizados na escola são momentos de aprender e se divertir ao mesmo tempo, pois o espaço e atividades são planejados de acordo com as dificuldades apresentadas pelo professor regente de cada aluno e vai evoluindo de acordo com as conquistas de cada um. De todo busca-se envolver os alunos nas atividades, proporcionando a eles uma autonomia significativa nas quais terão a possibilidade de ampliar o conhecimento.

É importante frisar que através do lúdico a criança aprende a agir, pois a curiosidade é estimulada e a mesma adquire maior autoconfiança aumentando a autoestima, o que melhora significativamente o desenvolvimento da linguagem, do pensamento e da concentração.

As atividades propostas são de caráter pedagógico, dando ênfase a um desenvolvimento mais elaborado que de fato sensibilize, a fim de motivar cada aluno envolvido na prática educativa.

É visível perceber o quanto o projeto tem a contribuir na vida de cada educando, pois sua concretização na escola faz com que alunos e pibidianas atinjam 
seus objetivos ao mesmo tempo. Ao aluno representa uma nova possibilidade de aprendizagem de conceitos não adquiridos em sala de aula e as acadêmicas pibidianas a oportunidade de confrontar a teoria aprendida na universidade com a prática do cotidiano escolar, pois ao se pensar no projeto, logo nos vêm à mente os alunos, a aprendizagem e a evolução dos mesmos, mas se esquece de avaliar as contribuições que ele faz na vida de cada acadêmico, ao perceber que o projeto vem preparar gradativamente todos os envolvidos.

O projeto contribui com a escola auxiliando nas necessidades que ela apresenta, estimulando e potencializando as capacidades dos alunos e lançando novos desafios as acadêmicas, tendo em vista que o mesmo é focado no reforço escolar por solicitação dos professores da instituição de ensino, sendo uma oportunidade para trabalhar com as dificuldades apresentadas pelos educandos e que merecem uma atenção individualizada.

São trabalhadas propostas referentes a dificuldades de leitura, escrita, interpretação e conceitos básicos da matemática. Através de metodologias diferenciadas e atividades lúdicas previamente definidas os alunos desenvolvem o gosto pelas propostas, tendo em vista, que o aluno que apresenta dificuldades muitas vezes está desestimulado por não se sentir incluído no processo de aprendizagem.

É um trabalho coletivo e que necessita de planejamento e determinação por partes das acadêmicas, oportunizando e vivenciando experiências da realidade escolar com comprometimento e responsabilidade. O Pibid é uma oportunidade das acadêmicas aproximarem-se da realidade escolar, vem ao encontro a uma educação inovadora, com intuito de formar um aluno crítico e ativo para conviver em sociedade, o trabalho diversificado e individual é uma forma de valorizar o ritmo de aprendizagem de cada aluno.

É necessário que se busque diferentes maneiras de ensinar, com uma interação integral por parte do professor, a fim de descobrir as causas dessas dificuldades e intervir para modificar e melhorar o processo cognitivo do aluno.

\section{RESULTADOS E DISCUSSÃO}

Além do trabalho coletivo no âmbito do Pibid ter alcançado um bom êxito, os dados coletados na pesquisa apontam para um significativo avanço na 
qualificação da formação das bolsistas de iniciação à docência no âmbito do projeto em análise, o qual vem interferindo positivamente não só na formação docente dos envolvidos no processo, mas na realidade escolar enquanto contribuição das acadêmicas a partir de novas metodologias, estratégias de ensino e diversificação de recursos didáticos, elementos que reverberam, também, no seu desenvolvimento pessoal e profissional, com consequente ampliação do leque de possibilidades de autoformarão e de atuação docente.

No que tange aos professores de carreira na educação básica, são unânimes em ressaltar as possibilidades formativas do Programa em tela, tanto para os alunos da licenciatura, quanto para o seu trabalho, uma vez que dá sustentação teórica e prática para o desenvolvimento de ações didático-pedagógicas na escola, além de atuar, ainda, sobre as dificuldades de aprendizagem dos estudantes da escola. Outrossim, indicam a importância de permanente diálogo entre universidade e escola para produção de estratégias de formação (inicial e continuada em serviço) dos professores e atuação docente como foco no desenvolvimento do aluno, uma vez que, para os professores pesquisados, a atuação dos pibidianos na escola trabalha no sentido de sua formação, mas também na potencialização das capacidades dos alunos, lançando desafios a eles e aos professores de carreira que já têm a docência como profissão.

No que tange aos alunos da escola, tendo em vista suas condições de vulnerabilidade social e econômica, o projeto analisado deu especial ênfase ao seu acompanhamento pedagógico, a fim de contribuir no desenvolvimento de suas aprendizagens e, por consequência, do seu rendimento escolar, incluindo em sua diversificação metodológica o lúdico, a música, a manipulação e observação de materiais concretos, privilegiando as características de sua fase de desenvolvimento e o tempo necessário para sua aprendizagem nos processos de alfabetização e letramento.

Ainda, podemos constatar as contribuições do Programa no sentido de movimentar a escola, levar os professores e a gestão pedagógica a repensarem seus momentos formativos e a (re) organização dos processos de ensinar e aprender na esfera de sua ação institucional, na perspectiva da dodiscência, defendida por Paulo Freire (ao ensinar se aprende e ao aprender se ensina), e também sob á ótica de Nóvoa (2007), sob a importância do regresso dos professores na condição de protagonistas de sua formação, enfocando a 
aprendizagem, e a integração entre sujeitos como desafio formativo em relação à diversidade de métodos apropriados para o ensino no atual contexto.

\section{CONSIDERAÇÕES FINAIS}

O Pibid é uma oportunidade de os estudantes de licenciaturas aproximarem-se da realidade escolar, no cotidiano do planejamento, execução e avaliação de propostas educativas. Vem ao encontro de uma educação inovadora, com intuito de formar professores críticos e pró-ativos para conviver em sociedade frente às demandas por ela apresentadas, visando a qualificação dos processos sociais. Por outro lado, consideramos a necessidade de avançar em percursos formativos que tenham na qualificação pessoal do professor o cerne para a constituição da docência e posterior transformação dos processos na escola de educação básica. (Trans)formar o professor em sujeito do processo formativo para qualificar a escola e os processos de formação daqueles que nela atuam e dela são beneficiários diretos ou indiretos.

\section{REFERÊNCIAS}

BARDIN, Laurence. Análise de conteúdo. Trad. Luís Antero Reto e Augusto Pinheiro. Ed. ver. e amp. São Paulo: Edições 70, 2011.

DAL'IGNA, M. C.Pibid/Capes: impactos de uma política de formação inicial na construção da identidade profissional da pedagoga (2013-2016). São Leopoldo: Programa de Pós-Graduação em Educação, Universidade do Vale do Rio dos Sinos. [Projeto de Pesquisa].

DAL'IGNA, M C.; FABRIS, E. H. Práticas de iniciação à docência noPibid/Unisinos: processo em avaliação. In: VIII do CONGRESSO INTERNACIONAL DE EDUCAÇÃO, 8., 2013, São Leopoldo; CONGRESSO INTERNACIONAL DE AVALIAÇÃO, 3., 2013, São Leopoldo: Universidade do Vale do Rio dos Sinos (Unisinos). 14p.

FABRIS, E. H.. A relação universidade e educação básica na produção da docência contemporânea (2013-2016). São Leopoldo: Programa de PósGraduação em Educação, Universidade do Vale do Rio dos Sinos. [Projeto de Pesquisa]. 2011

FABRIS, E. H. A qualidade da educação superior nas licenciaturas: estratégias de profissionalização docente durante o curso de formação inicial (09/2013- 
02/2014). São Leopoldo: Programa de Pós- Graduação em Educação, Universidade do Vale do Rio dos sinos Unisinos. [Projeto de Pesquisa Pós-Doutorado]. 2014.

NÓVOA, António. O regresso dos professores. Lisboa: Repositório da Universidade de Lisboa, 2007

NÓVOA ,António. Professores imagens do presente .Lisboa:Relgráficaartes gráficas, Benedita, 2009. 